

Archives of Plastic Surgery

\title{
Platybasia in 22q11.2 Deletion Syndrome Is Not Correlated with Speech Resonance
}

\author{
Nicole E Spruijt, Moshe Kon, Aebele B Mink van der Molen \\ Department of Plastic Surgery, University Medical Center, Utrecht, The Netherlands
}

Background An abnormally obtuse cranial base angle, also known as platybasia, is a common finding in patients with 22q11.2 deletion syndrome (22q11DS). Platybasia increases the depth of the velopharynx and is therefore postulated to contribute to velopharyngeal dysfunction. Our objective was to determine the clinical significance of platybasia in 22q11DS by exploring the relationship between cranial base angles and speech resonance.

Methods In this retrospective chart review at a tertiary hospital, 24 children (age, 4.0-13.1 years) with 22q11.2DS underwent speech assessments and lateral cephalograms, which allowed for the measurement of the cranial base angles.

Results One patient (4\%) had hyponasal resonance, 8 (33\%) had normal resonance, 10 (42\%) had hypernasal resonance on vowels only, and $5(21 \%)$ had hypernasal resonance on both vowels and consonants. The mean cranial base angle was $136.5^{\circ}$ (standard deviation, $5.3^{\circ}$; range, $122.3-144.8^{\circ}$ ). The Kruskal-Wallis test showed no significant relationship between the resonance ratings and cranial base angles $(P=0.242)$. Cranial base angles and speech ratings were not correlated (Spearman correlation $=0.321, P=0.126$ ). The group with hypernasal resonance had a significantly more obtuse mean cranial base angle $\left(138^{\circ}\right.$ vs. $\left.134^{\circ}, P=0.049\right)$ but did not have a greater prevalence of platybasia $(73 \%$ vs. 56\%, $\mathrm{P}=0.412)$.

Conclusions In this retrospective chart review of patients with 22q11DS, cranial base angles were not correlated with speech resonance. The clinical significance of platybasia remains unknown.

\section{Keywords DiGeorge syndrome / Platybasia / Velopharyngeal insufficiency}

\author{
Correspondence: Nicole E Spruijt \\ Department of Plastic Surgery, \\ University Medical Center Utrecht, \\ KE 04.140.0, Postbus 85090, 3508 AB \\ Utrecht, The Netherlands \\ Tel: +31887554004 \\ Fax: +31887555516 \\ E-mail: nespruijt@gmail.com
}

Received: 21 Jan 2014 • Revised: 19 Feb 2014 • Accepted: 26 Feb 2014

pISSN: 2234-6163 • elSSN: 2234-6171 • http://dx.doi.org/10.5999/aps.2014.41.4.344 • Arch Plast Surg 2014;41:344-349

No potential conflict of interest relevant to this article was reported.

\section{INTRODUCTION}

The hemizygous deletion of a region on the long arm of the 22nd chromosome results in a series of physical and mental ailments collectively known as the $22 \mathrm{q} 11.2$ deletion syndrome (22q11DS, OMIM \#192430/188400) [1]. Genes in this region contribute to, amongst others, the embryonic development of pharyngeal arches 3,4 , and 6 . Therefore, deletion of these genes often leads to dysmorphism and/or dysfunction of structures that are derived from these pharyngeal arches including the face, velum, parathyroid, thymus, and heart.

The phenotype varies greatly among patients but often includes hypernasal speech due to velopharyngeal dysfunction (VPD). Many factors may contribute to the etiology of the VPD in 22q11DS [2]. An abnormally obtuse cranial base angle, also known as platybasia, is a common finding in 22q11DS [3-5]. Platybasia increases the depth of the velopharynx and is therefore postulated to contribute to VPD [6]. 
In the sagittal midline of the skull, the frontal, ethmoid, sphenoid, and occipital bones form the cranial base angle. During embryology, neural crest cells migrating from the region of the hindbrain to pharyngeal arches 3,4 , and 6, which are known to be affected in 22q11DS, pass through the region that becomes the skeletal cranial base [7]. In the general population, between the ages of 6 and 21 years, the cranial base angle remains stable in females and decreases only slightly in males [8].

Mechanical forces increase chondrocyte proliferation and cranial base growth [9-11]. Hypothetically, since pharyngeal muscles influence the size and shape of the cranial base, weakness of the muscles may cause a tendency towards platybasia [6]. Continuing in this line of thought, surgical treatment of VPD, which involves rotating velopharyngeal muscles, could potentially decrease the cranial base angle by tethering the posterior pharyngeal wall to the velum (as in a pharyngeal flap procedure) or constriction (as in sphincter pharyngoplasty).

Velopharyngeal muscle hypotonia and surgery for VPD may affect the cranial base angles in patients with 22q11DS. However, thus far, the clinical significance of platybasia has not been shown [3]. Studies in which the cranial base angle was discussed in the context of speech problems only assessed cohorts of patients with hypernasal speech [12-15] or those requiring surgery for VPD [16]. The objective of this study was to explore the relationship between cranial base angles in patients with 22q11DS and speech resonance or previous palato- and/or pharyngoplasty. We hypothesized that patients with hypernasal speech would have more obtuse cranial base angles. In addition, patients with previous palato- or pharyngoplasties were expected to have more acute cranial base angles.

\section{METHODS}

\section{Patients}

The cranial base angle can be measured on lateral cephalograms. Lateral cephalograms are not routinely taken for all patients with 22q11DS who attend the multidisciplinary outpatient clinic at our tertiary referral center. At the discretion of the orthodontist in the multidisciplinary team, many patients have had lateral cephalograms taken in conjunction with dental panoramic radiographs. The hospital's electronic patient database allowed access to lists of patients who attended the clinic in the past 21 months (March 2012-November 2013). A search in this electronic database yielded 24 patients with 22q11DS who had a lateral cephalogram and whose speech was assessed by a speech-language pathologist in the team. In accordance with the Health Code of 2005 based on the Code of Good Conduct 1995, our institutional review board grants a universal waiver for retrospective chart reviews, such as this study, in which patient data are completely anonymous and not identifiable.

\section{Power calculation}

Using an alpha of 0.05 and a power of 0.80 , we found that the sample size of 24 patients was sufficient to find a correlation coefficient rho of 0.5 .

\section{Speech evaluation}

The speech-language pathologists in our multidisciplinary team are specialized in assessing cleft speech. They rated the perceptual resonance of patients' speech using the three-point scale used by the Dutch Association for Cleft and Craniofacial Anomalies [17]: A score of 1 denotes that normal resonance is heard on vowels. A score of 2 denotes that hypernasal resonance is heard on vowels only. A score of 3 denotes that hypernasal resonance is heard on vowels and weak consonants (for example, [b, d, k] are heard as [m, n, ng]). In this study, a score of 0 was added for resonance that was deemed hyponasal.

\section{Cranial base angle}

On the lateral cephalogram, the angle $\left(^{\circ}\right)$ was measured for nasion-sella turcica-basion [8] using ImageJ software (version 1.46r, National Institutes of Health, USA) (Fig. 1). The assessor was blinded to the participant's age, gender, surgical history, and

\section{Fig. 1. Lateral cephalogram}

The arrows indicate the points where the cranial base angle was measured.

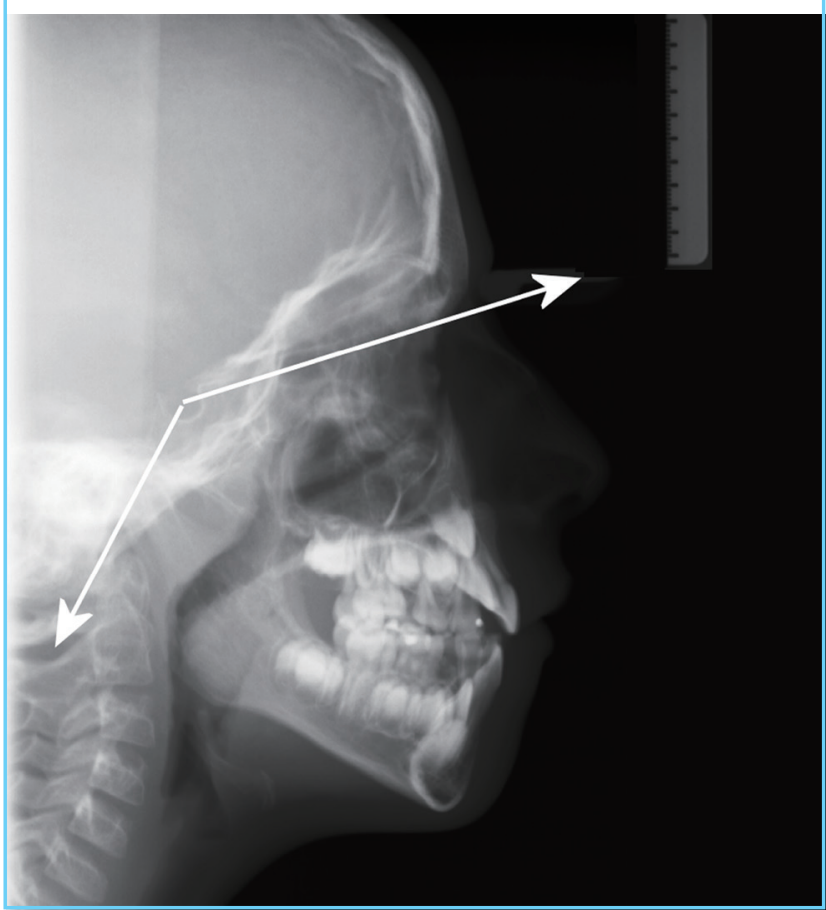


resonance rating. The accuracy of the measurements was tested by repeating measurements on all lateral cephalograms on two separate occasions that were at least three weeks apart. The intraclass correlation coefficient of duplicate measurements was 0.94 , denoting excellent intra-observer reliability.

There is no agreed threshold cranial base angle to define platybasia. Some refer to the normal range of $128.9^{\circ}-131.6^{\circ}$ with a standard deviation (SD) of approximately $5^{\circ}$ [13]. By defining platybasia as a cranial base angle that is $1 \mathrm{SD}$ more obtuse than the mean cranial base angle, a cranial base angle of $>136^{\circ}$ was considered platybasia in this study [3].

\section{Outcomes}

Two-tailed Spearman correlations were performed between 1) cranial base angles and resonance ratings, 2) cranial base angles and ages, and 3) ages and resonance ratings. To further assess the relationship between speech resonance and the cranial base angle, the Kruskal-Wallis test was performed. Demographics and cranial base angles were compared between the groups of patients with normal resonance (rating, $\leq 1$ ) and those with hypernasal resonance (rating, > 1) by using the Mann-Whitney $\mathrm{U}$, chi-squared, or Fisher's exact test where appropriate. Addition- ally, demographics and resonance ratings were compared between the group of patients with normal cranial base angles and those with platybasia by using the Mann-Whitney U, chisquared, or Fisher's exact test where appropriate. Statistical calculations were performed using SPSS Statistics for Windows ver. 20.0. (IBM Inc., Armonk, NY, USA), where $\mathrm{P}<0.05$ was considered a significant finding.

\section{RESULTS}

The 24 patients who had lateral cephalograms and speech assessments had a mean age of 8.3 years (SD, 2.2 years; range, 4.0-13.1 years). Thirteen (54\%) were female. One (4\%) had hyponasal resonance, 8 (33\%) had normal resonance, 10 (42\%) had hypernasal resonance on vowels only, and 5 (21\%) had hypernasal resonance on vowels and consonants. Cleft palate and surgical history is listed in Table 1. Patients who were found to have a cleft palate but had not undergone palatoplasty (all had submucous cleft palates) were on the waiting list for a modified Honig pharyngoplasty, which includes a velar pushback. The mean cranial base angle was $136.5^{\circ}\left(\mathrm{SD}, 5.3^{\circ}\right.$; range, $\left.122.3^{\circ}-144.8^{\circ}\right)$. The Kruskal-Wallis test showed no significant relationship between

\begin{tabular}{|c|c|c|c|c|c|c|c|}
\hline \multirow[b]{2}{*}{ Factor } & \multirow{2}{*}{$\begin{array}{l}\text { All patients } \\
(n=24)\end{array}$} & \multicolumn{3}{|c|}{ Resonance } & \multicolumn{3}{|c|}{ Cranial base angle } \\
\hline & & $\begin{array}{c}\text { Normal } \\
(n=9)\end{array}$ & $\begin{array}{l}\text { Hyper-nasal } \\
(n=15)\end{array}$ & P-value & $\begin{array}{c}\text { Normal } \\
(n=8)\end{array}$ & $\begin{array}{l}\text { Platy-basia } \\
(n=16)\end{array}$ & P-value \\
\hline Age (yr) & $\begin{array}{l}8.3 \pm 2.2 \\
(4.0-13.1)\end{array}$ & $\begin{array}{l}9.8 \pm 1.8 \\
(6.7-13.1)\end{array}$ & $\begin{array}{l}7.4 \pm 1.9 \\
(4.0-10.9)\end{array}$ & $0.009^{a)}$ & $\begin{array}{l}8.9 \pm 2.6 \\
(5.9-13.1)\end{array}$ & $\begin{array}{l}8.0 \pm 2.0 \\
(4.0-11.1)\end{array}$ & $0.426^{\text {a) }}$ \\
\hline Female & $13(54)$ & $4(44)$ & $9(60)$ & $0.675^{\text {b) }}$ & $4(50)$ & $9(56)$ & $1.000^{b)}$ \\
\hline Cleft palate & & & & $0.027^{c)}$ & & & $0.665^{c)}$ \\
\hline No & $16(67)$ & $9(100)$ & $7(47)$ & & $5(63)$ & $11(69)$ & \\
\hline Submucous cleft palate & 7 (29) & $0(0)$ & $7(47)$ & & $3(37)$ & $4(25)$ & \\
\hline Cleft lip and palate & $1(4)$ & $0(0)$ & $1(6)$ & & $0(0)$ & $1(6)$ & \\
\hline Palatoplasty & & & & $0.027^{c)}$ & & & $0.936^{c)}$ \\
\hline No cleft & $16(67)$ & $9(100)$ & $7(47)$ & & $5(63)$ & $11(69)$ & \\
\hline Cleft, but no palatoplasty & $3(12)$ & $0(0)$ & $3(20)$ & & $1(12)$ & $2(12)$ & \\
\hline Palatoplasty & $5(21)$ & $0(0)$ & $5(33)$ & & $2(25)$ & $3(19)$ & \\
\hline Pharyngoplasty & & & & $0.015^{c)}$ & & & $0.163^{c)}$ \\
\hline No & $9(38)$ & $4(44)$ & $5(33)$ & & $5(62)$ & $4(25)$ & \\
\hline Waiting list & $8(33)$ & $0(0)$ & $8(53)$ & & $1(13)$ & $7(44)$ & \\
\hline Yes & $7(29)$ & $5(56)$ & $2(13)$ & & $2(25)$ & $5(31)$ & \\
\hline Resonance & & & & $0.000^{c)}$ & & & $0.397^{c)}$ \\
\hline Hyponasal & $1(4)$ & $1(11)$ & $0(0)$ & & $1(12)$ & $0(0)$ & \\
\hline Normal & $8(33)$ & $8(89)$ & $0(0)$ & & $3(38)$ & $5(31)$ & \\
\hline Hypernasal vowels only & $10(42)$ & $0(0)$ & $10(67)$ & & $2(25)$ & $8(50)$ & \\
\hline Hypernasal vowels and consonants & $5(21)$ & $0(0)$ & $5(33)$ & & $2(25)$ & $3(19)$ & \\
\hline Cranial base angle & $\begin{array}{l}136 \pm 5 \\
(122-145)\end{array}$ & $\begin{array}{l}134 \pm 4 \\
(128-139)\end{array}$ & $\begin{array}{l}138 \pm 6 \\
(122-145)\end{array}$ & $0.049^{\text {a) }}$ & $\begin{array}{l}131 \pm 5 \\
(122-136)\end{array}$ & $\begin{array}{l}139 \pm 3 \\
(137-145)\end{array}$ & $0.000^{\mathrm{a})}$ \\
\hline Platybasia & $16(67)$ & $5(56)$ & $11(73)$ & $0.412^{\mathrm{b})}$ & $0(0)$ & $16(100)$ & $0.000^{b)}$ \\
\hline
\end{tabular}


the resonance ratings and cranial base angles $(\mathrm{P}=0.242)$.

Cranial base angles and resonance ratings were not correlated (Spearman correlation $=0.321, \mathrm{P}=0.126$ ), nor were age and cranial base angles (Spearman correlation $=-0.264, \mathrm{P}=0.212$ ) However, age and resonance ratings were correlated: older patients had more normal resonance $($ Spearman correlation $=$


(B)

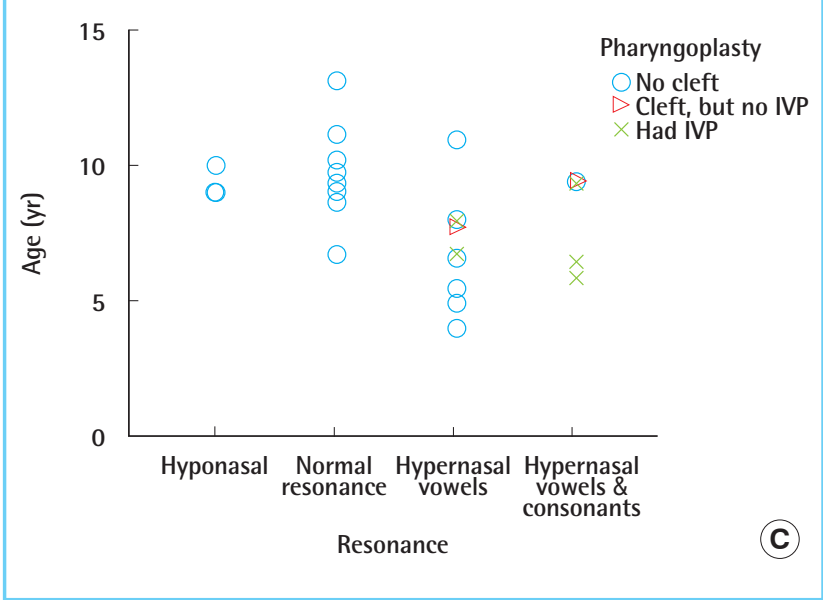

-0.419, $\mathrm{P}=0.042$ ) (Fig. 2).

Comparing participants with normal resonance (rating, $\leq 1$; $\mathrm{n}=9$ ) to those with hypernasal resonance (rating, $>1 ; n=15$ ) showed significant demographic differences (Table 1). Patients with normal resonance were significantly older $(\mathrm{P}=0.009)$, had no cleft palates or palatoplasties $(\mathrm{P}=0.027)$, and were not on the waiting list for a pharyngoplasty $(\mathrm{P}=0.015)$. The group with hypernasal resonance had a significantly more obtuse mean cranial base angle $\left(138^{\circ}\right.$ vs. $\left.134^{\circ}, \mathrm{P}=0.049\right)$ but did not have a greater prevalence of platybasia $(73 \%$ vs. $56 \%, \mathrm{P}=0.412)$.

Comparing participants with normal cranial base angles $\left(\leq 136^{\circ}, n=8\right)$ to those with platybasia $\left(>136^{\circ}, n=16\right)$ showed no significant demographic differences or differences in resonance $(\mathrm{P}=0.397)$ (Table 1$)$.

\section{DISCUSSION}

The role of platybasia in the etiology of VPD was suggested over a half century ago [18]. Yet, to date, the clinical significance of platybasia in patients with 22q11DS has not been shown [3]. In this retrospective chart review of patients with 22q11DS, cranial base angles were not correlated with speech resonance. However, we did find a trend toward the mean cranial base angle being more obtuse in the group of patients with hypernasal speech.

While the meaning of platybasia is clear (literally, "flat skull"), there is no standardized definition. Some have reported platybasia in patients with 22q11DS with respect to a control group [5$7,13,19,20]$. Others have used cut-off values, defining platybasia as $7^{\circ}[21]$ or $10^{\circ}[16]$ above the normal mean without specifying SDs. Still others have defined platybasia as being $1 \mathrm{SD}$ $[3,12,13], 1.5 \mathrm{SD}[4]$, or $2 \mathrm{SD}$ above the normal mean. The choice to define platybasia as $1 \mathrm{SD}$ above the normal mean was somewhat arbitrary. The lack of correlation of the cranial base angle with the resonance rating (Fig. 2) provides more insight into the, thus far, clinical non-significance of measuring the cranial base angle.

The finding that speech problems are not correlated with platybasia is echoed by another syndrome that is characterized by a high prevalence of platybasia: Hajdu-Cheney Syndrome. Patients with this syndrome have platybasia but do not have VPD; the symptoms that are attributed to platybasia include headaches, hydrocephalus, poor balance, dizziness, muscle weakness, decreased sensitivity to pain and temperature, and vision loss [22]. In our current study, we did not assess these symptoms in patients with 22q11DS.

Potential factors affecting the cranial base angles in 22q11DS are the presence of a cleft palate and/or a history of palato- and/ or pharyngeal surgery. A recent large study showed that the 
prevalence of platybasia decreases successively from patients with occult submucous cleft palate to submucous cleft palate to cleft palate to cleft lip and palate [13], perhaps reflecting the effect of differing degrees of surgical correction. However, young adults with repaired unilateral cleft lip and palate still have more obtuse cranial base angles than the control group [23], suggesting that no effect of surgical correction overcomes a congenitally obtuse angle. We did not find a significant relationship between cleft palate and platybasia, nor palatoplasty and platybasia.

The lack of correlation of the cranial base angle with palatoand/or pharyngoplasties found in this study is confirmed by others who studied patients without 22q11DS. Although not a longitudinal study, in this study, the cranial base angles of males without a cleft palate were compared to those of boys with an unrepaired cleft palate, and those of boys whose cleft palates were repaired with a pushback and pharyngeal flap. The cranial base angles did not differ significantly between the groups [24]. In another study, the cranial base angles did not differ between children with unilateral cleft lip or cleft palate and the control group at the ages of 4 months and 2, 4, and 8 years, suggesting that the growth of the cranial base is not considerably influenced by surgical intervention [25].

In conclusion, in this study, among patients with 22q11DS, while we found that patients with hypernasal speech had a significantly more obtuse mean cranial base angle, the prevalence of platybasia among these patients was not significantly greater, and there was no correlation between resonance and the cranial base angle. The clinical significance of platybasia remains unknown. The etiology of VPD in 22q11DS is multifaceted [2] and is likely to be a sum of many factors. Our findings indicate that platybasia does not play a prominent role in VPD.

\section{REFERENCES}

1. Shprintzen RJ. Velo-cardio-facial syndrome: 30 Years of study. Dev Disabil Res Rev 2008;14:3-10.

2. Widdershoven JC, Beemer FA, Kon M, et al. Possible mechanisms and gene involvement in speech problems in the 22q11.2 deletion syndrome. J Plast Reconstr Aesthet Surg 2008;61:1016-23.

3. Ricchetti ET, States L, Hosalkar HS, et al. Radiographic study of the upper cervical spine in the 22q11.2 deletion syndrome. J Bone Joint Surg Am 2004;86:1751-60.

4. Ruotolo RA, Veitia NA, Corbin A, et al. Velopharyngeal anatomy in 22q11.2 deletion syndrome: a three-dimensional cephalometric analysis. Cleft Palate Craniofac J 2006;43: 446-56.

5. Heliovaara A, Hurmerinta K. Craniofacial cephalometric morphology in children with CATCH 22 syndrome. Orthod Craniofac Res 2006;9:186-92.

6. Arvystas M, Shprintzen RJ. Craniofacial morphology in the velo-cardio-facial syndrome. J Craniofac Genet Dev Biol 1984;4:39-45.

7. Molsted K, Boers M, Kjaer I. The morphology of the sella turcica in velocardiofacial syndrome suggests involvement of a neural crest developmental field. Am J Med Genet A 2010; 152:1450-7.

8. Axelsson S, Kjaer I, Bjornland T, et al. Longitudinal cephalometric standards for the neurocranium in Norwegians from 6 to 21 years of age. Eur J Orthod 2003;25:185-98.

9. Cohen MM Jr. Malformations of the craniofacial region: evolutionary, embryonic, genetic, and clinical perspectives. Am J Med Genet 2002;115:245-68.

10. Persing JA, Morgan EP, Cronin AJ, et al. Skull base expansion: craniofacial effects. Plast Reconstr Surg 1991;87:102833.

11. Wang X, Mao JJ. Chondrocyte proliferation of the cranial base cartilage upon in vivo mechanical stresses. J Dent Res 2002;81:701-5.

12. Havkin N, Tatum SA, Shprintzen RJ. Velopharyngeal insufficiency and articulation impairment in velo-cardio-facial syndrome: the influence of adenoids on phonemic development. Int J Pediatr Otorhinolaryngol 2000;54:103-10.

13. Nachmani A, Aizenbud D, Berger G, et al. The prevalence of platybasia in patients with velopharyngeal incompetence. Cleft Palate Craniofac J 2013;50:528-34.

14. Leveau-Geffroy S, Perrin JP, Khonsari RH, et al. Cephalometric study of the velocardiofacial syndrome: Impact of dysmorphosis on phonation. Rev Stomatol Chir Maxillofac 2011;112:11-5.

15. Wang K, Yang Y, Shen F, et al. Utilization of three-dimensional computed tomography for craniofacial phenotypic analysis in children with velocardiofacial syndrome. J Craniofac Surg 2009;20:2013-9.

16. Veerapandiyan A, Blalock D, Ghosh S, et al. The role of cephalometry in assessing velopharyngeal dysfunction in velocardiofacial syndrome. Laryngoscope 2011;121:732-7.

17. Meijer MF. Testing speech of children born with a cleft. In: A report from the Speech therapy workgroup from the Dutch Association for Cleft Palate and Craniofacial Anomalies. Amsterdam (NL): Vrije Universiteit Medisch Centrum; 2003.

18. Ricketts RM. The cranial base and soft structures in cleft palate speech and breathing. Plast Reconstr Surg (1946) 1954; $14: 47-61$.

19. Dalben Gda S, Richieri-Costa A, Taveira LA. Craniofacial 
morphology in patients with velocardiofacial syndrome. Cleft Palate Craniofac J 2010;47:241-6.

20. Glander K 2nd, Cisneros GJ. Comparison of the craniofacial characteristics of two syndromes associated with the Pierre Robin sequence. Cleft Palate Craniofac J 1992;29:210-9.

21. Oberoi S, Vargervik K. Velocardiofacial syndrome with single central incisor. Am J Med Genet A 2005;132:194-7.

22. Brennan AM, Pauli RM. Hajdu--Cheney syndrome: evolution of phenotype and clinical problems. Am J Med Genet 2001;100:292-310.
23. Dogan S, Oncag G, Akin Y. Craniofacial development in children with unilateral cleft lip and palate. Br J Oral Maxillofac Surg 2006;44:28-33.

24. Smahel Z, Mullerova I. Nasopharyngeal characteristics in children with cleft lip and palate. Cleft Palate Craniofac J 1992;29:282-6.

25. Han BJ, Suzuki A, Tashiro H. Longitudinal study of craniofacial growth in subjects with cleft lip and palate: from cheiloplasty to 8 years of age. Cleft Palate Craniofac J 1995;32: 156-66. 